\title{
Reactivated world war two traumatic memories in COVID19 lock down period
}

\author{
Inès Bigarré ${ }^{1}$, Caroline Landon ${ }^{1}$, Pierre Boyer ${ }^{2}$, and Julie Dupouy ${ }^{2}$ \\ ${ }^{1}$ MSPU Pins Justaret \\ ${ }^{2}$ Université Paul Sabatier Toulouse III - Faculté de Médecine Rangueil
}

September 28, 2020

\begin{abstract}
Lockdown measures because of COVID-19 pandemic have had a major impact on patients' mental health. We present the case of an 80-year-old patient, reactivating World War Two memories during lockdown period. We looked for posttraumatic stress disorder (PTSD). She also presented with a rheumatoid arthritis flare after disease control
\end{abstract}

\section{Key Clinical Message}

Some events that we can forget about can still have an impact on elderly people's health. Asking about patients' feelings and past experiences during such conditions may help them express their feelings, and they may ask for psychological help.

\section{Keywords}

Post traumatic stress disorder, 19391945 world war

\section{Introduction}

The COVID-19 pandemic gave birth to an unexpected situation worldwide. Though some were well prepared, lockdown measures in France have had a major impact on patients' mental health, whether they already had a psychiatric history or not.

While other authors have reported psychiatric decompensating due to COVID-19 confinement measures ${ }^{1,2}$, we have not yet not thought much about elderly patients, particularly those who lived in occupied France between 1939 and 1945 .

Here, we present the case of a patient with reactivated war memories during the COVID-19 lockdown period, presenting with a rheumatoid arthritis flare after disease control without any drugs since 2015.

\section{Case history}

Ms. F., an 80-year-old woman, came to the office on April $14^{\text {th }}$. She presented with joint stiffness, finger and hip articular pain, and notable asthenia. At the beginning of May, she then started to have a fever of approximately $38^{\circ} \mathrm{C}$. On examination, her vitals were as follows: heart rate 100 beats per minute and blood pressure 130/70 mmHg. Her pain prevented her from sleeping, her asthenia persisted, and her CRP was elevated. Given the situation, we decided to treat her with prednisolone and send her to her referring rheumatologist. The latter confirmed that she was having a rheumatoid arthritis flare and prescribed corticoids until September. 
This woman was known to have rheumatoid arthritis since 2012, when she had her first flare. At this time, her rheumatologist introduced cortisone and methotrexate. In 2015, she was stable under this therapy, and her treatment was stopped. Since 2015, she has had no symptoms at all of her condition, without any medication.

No potential organic cause of this arthritis flare has been found. However, when speaking din depth with the patient, she told us interesting details about her feelings regarding the lockdown measures. As a matter of fact, she retrospectively noticed that, from March $16^{\text {th }}$ to May $11^{\text {th }}$, her feelings were "anesthetized", and the confinement measures reminded her of her World War Two (WWII) habits.

Ms. F. grew up in a village under German occupation during WWII. At the consultation, she expressed she felt like she has had a growing "fear of the Germans" every day. During the COVID-19 lockdown period, her papers were controlled each time she left her house. In particular, she was controlled when she went to the next village to tend to some errands that could not be done in her village, which reminded her of the "open cities" during WWII.

Additionally, she did not at all expect the lockdown measures. Getting back from holiday, she turned on TV and heard "this is war". Her son came immediately, telling her that he was "not sure when we will see each other again ". Her daughter came the next day to say goodbye too. Ms. F. was an active person in her village, but all of her social activities were stopped.

\section{Investigations}

As soon as she verbalized the memories coming back from WWII, we looked for potential posttraumatic stress disorder (PTSD) using the Posttraumatic Stress Disorder Checklist Scale (PCL 5), DSM-5 version. We did not find significant PTSD; her total score of 17 (from 0 to 80), with most of the points concerned with three criteria: "Loss of interest in activities that you used to enjoy", "Feeling distant or cut off from other people", and "Trouble experiencing positive feelings (for example, being unable to feel happiness or have loving feelings for people close to you)".

A total score between 31 and 33 suggests probable $\mathrm{PTSD}^{3}$; in this case, the lack of avoidance, intrusive symptoms and hyperarousal forces us to believe there was no PTSD for this patient. Hence, a provisional PTSD diagnosis could not be made because there were no moderate or higher symptoms apart from cluster D symptoms, which represent negative symptoms for PTSD according to the DSM-5.

However, Ms. F. had previously reported real flashbacks before the COVID-19 pandemic. She relived German interrogation while being at a friend's doctor appointment. She was accompanying her but did not know why her friend needed her. During the appointment, her friend related private information, and Ms. F. had an intrusive symptom, felling like she was reliving a German interrogatory. She froze and could not move from her chair anymore. According to her, the health professionals who were there had to stimulate her until she came out of this flashback and could move again.

We did not interrogate Ms. F. about a potential PTSD diagnosis before the lockdown period. If her score was down to zero before COVID-19, we would think that this period had a real impact on her psychological quality of life. Additionally, elderly patients can have very nonspecific symptoms ${ }^{4}$.

\section{Discussion}

This case is an interesting one to think about mental health prevention in elderly patients' during unexpected major events. Indeed, older patients have a past that practitioners did not live, such as having experienced World War Two. We may forget about these events, but they still have an impact on elderly people's quality of life and health. Different studies have found a significant impact of WWII on both mental disorder prevalence and physical morbidity ${ }^{5}$. Additionally, past trauma can create delayed and nonclassical symptoms in the elderly ${ }^{4}$. In this precise case, even though we could not find any link between the patient's rheumatologic conditions and her past resurgence during lockdown, we imagine that any psychological support would likely have been appreciated. Indeed, asking about patients' feelings and past experiences during such unique conditions may help them express their feelings, and they may ask for psychological help. In the particular 
case of COVID-19 lockdown, a patient who may have been thinking the whole time that the lockdown measures were "an order" could have been reassured if a healthcare professional could explain than those measures were national health measures rather than real war conditions.

\section{Conflict of interest}

None

\section{Author Contributions}

Inès Bigarré: Have made substancial contributions to conception and design, and been involved in drafting the manuscript, and given final approval of the version to be published, and agreed to be accountable for all aspects of the work in ensuring that questions related to the accuracy or integrity of any part of the work are appropriately investigated and resolved.

Caroline Landon: Have made substancial contributions to conception and design, and given final approval of the version to be published, and agreed to be accountable for all aspects of the work in ensuring that questions related to the accuracy or integrity of any part of the work are appropriately investigated and resolved.

Pierre Boyer: Have made substancial contributions to conception and design, and given final approval of the version to be published, and agreed to be accountable for all aspects of the work in ensuring that questions related to the accuracy or integrity of any part of the work are appropriately investigated and resolved.

Julie Dupouy: Have made substancial contributions to conception and design, and been involved in drafting the manuscript, and given final approval of the version to be published, and agreed to be accountable for all aspects of the work in ensuring that questions related to the accuracy or integrity of any part of the work are appropriately investigated and resolved.

\section{Acknowledgments}

We would like to thank Ms. F for trusting us to report her case.

\section{References}

1- Fischer, M., Coogan, A.N., Faltraco, F., and Thome, J. 2020. COVID-19 paranoia in a patient suffering from schizophrenic psychosis - a case report. Psychiatry Res 288,113001.

2- Huarcaya-Victoria, J., Herrera, D., Castillo, and C. 2020. Psychosis in a patient with anxiety related to COVID-19: A case report. Psychiatry Res 289,113052.

3- Weathers, F.W., Litz, B.T., Keane, T.M., Palmieri, P.A., Marx, B.P., and Schnurr, P.P. The PTSD Checklist for DSM-5 (PCL-5). The National Center for PTSD 2013. www.ptsd.va.gov. Accessed September 26,2020 .

4- Ladson, D., Bienenfeld, D. 2007. Delayed Reaction to Trauma in an Aging Woman. Psychiatry (Edgmont) $4,46-5$.

5- Glaesmer, H., Brähler, E., Gündel, H., and Riedel-Heller, S.G. 2011. The Association of Traumatic Experiences and Posttraumatic Stress Disorder With Physical Morbidity in Old Age: A German Population-Based Study. Psychosomatic Medicine 73,401-406.

6- Kuwert, P., Braehler, E., Freyberger, H.J., and Glaesmer, H. 2012. More Than 60 Years Later: The Mediating Role of Trauma and Posttraumatic Stress Disorder for the Association of Forced Displacement in World War II With Somatization in Old Age. The Journal of Nervous and Mental Disease 200, 911-914. 